\title{
Atropine and paralytic ileus
}

\author{
NEIL BEATSON \\ M.B., B.S. \\ Department of Surgery, Royal South Hants Hospital, Southampton
}

\section{Summary}

A patient who developed paralytic ileus while on atropine therapy is described, and this complication of atropine-like drugs is reviewed.

\section{Introduction}

Drugs are an important cause of paralytic ileus and failure to recognize this may lead to unnecessary laparotomy. Atropine is an anti-muscarinic alkaloid and its action in decreasing the motility of intestine is well known.

However, paralytic ileus as a complication of atropine therapy has not to my knowledge previously been reported.

\section{Case report}

A 77-year-old man was admitted from a nearby geriatric unit with a 24-hr history of vomiting and epigastric pain. He had previously been well, although limited by Parkinson's disease which was controlled with Sinemet 275 (levodopa and carbidopa) one tablet daily.

For the previous 4 months, distressing excessive salivation had been successfully treated with $0.6 \mathrm{mg}$ atropine sulphate daily given orally. $\mathrm{He}$ was also taking bendrofluazide $5 \mathrm{mg}$ daily, slow $\mathrm{K} 2$ tablets daily and indomethacin $25 \mathrm{mg}$ twice daily.

He had not demonstrated any signs of excessive anticholinergic activity before his present illness and occasionally had needed Lomotil (atropine and diphenoxylate) for bouts of loose bowel motions which were not thought to be significant.

Examination revealed a withdrawn, dehydrated patient with a slightly distended abdomen and absent bowel sounds. He showed tenderness without guarding in the epigastrium. There were no other demonstrable signs of atropine poisoning; his heart rate was regular 56 per min. The pupils were not dilated, the skin was of normal temperature and colour and his mental state, although depressed, was thought to be due to the combination of his Parkinson's disease and dehydration.
Biochemical and haematological investigations were all unremarkable. Plain X-rays of the abdomen showed massive dilatation of stomach and small intestine (Fig. 1).

All drugs were stopped and conservative treatment was commenced with nasogastric aspiration and intravenous fluid replacement. By the fourth day after admission the patient was much improved, taking oral fluids, having a normal bowel action and much more alert.

Repeat plain abdominal X-rays showed the bowel to have been decompressed. The patient was recommenced on his previous medication minus the atropine.

\section{Discussion}

George (1980) has recently reviewed drugs causing intestinal obstruction and mentions that atropine-like compounds do not usually give rise to problems, except in overdose or when combined with an opiate. Indeed, standard textbooks of pharmacology suggest that the dosage of atropine necessary to suppress the motility of the gastrointestinal tract is greater than that necessary either to block salivary secretion or increase the heart rate.

However, earlier literature suggests that often the dosage and the length of therapy do not play a significant part in the development of the ileus for ganglion blocking drugs (Munster and Milton, 1961) or amitriptyline (Milner and Buckler, 1964). The case described here would appear to support this view.

Anti-cholinergic activity is a property of many drugs and most notably the tricyclic anti-depressants have been reported as causing paralytic ileus (Milner and Buckler, 1964; Milner and Hills, 1966).

Phenothiazines, specifically chlorpromazine, are also a recognized cause, thought to be due to their weak atropinic properties (Sriram et al., 1979). However, with this latter group of drugs it is thought that the development of the ileus is dose related, as it is most often seen in the mentally disturbed patient who may be on huge doses of chlorpromazine. 


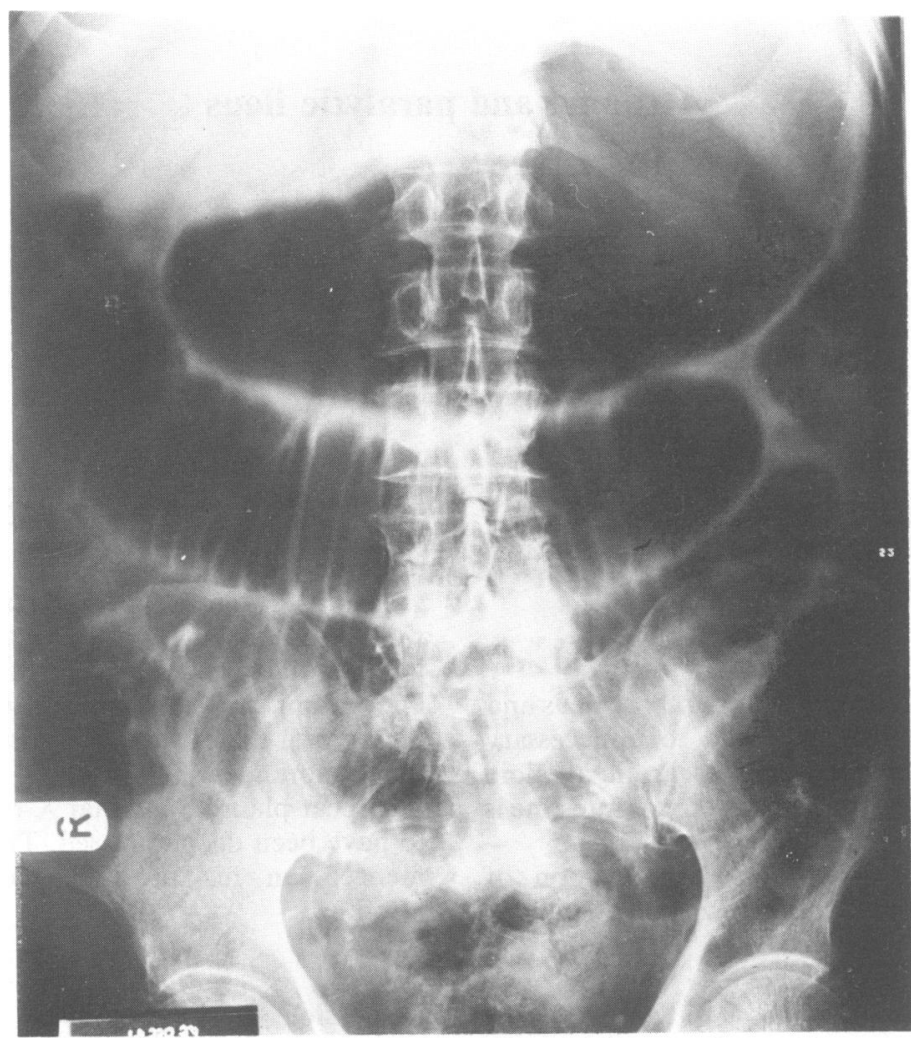

FIG. 1. supine abdominal X-ray showing dilatation of stomach and small bowel.

Haloperidol, another neuroleptic drug has also been incriminated (Maltbie et al., 1981). Phenothiazines may also act to cause ileus via their anti-histaminic properties. Histamine is thought to act directly or indirectly to stimulate gastrointestinal motility (George, 1980), although with one exception (Watson, Knutty and Colclough, 1977) the $\mathrm{H}_{2}$ antagonists have not been incriminated. Parkinson's disease itself may cause constipation (Simpson, 1978), and thus patients receiving anticholinergic therapy for Parkinson's disease are more prone to ileus by the very nature of their disease (Daggett and Ibrahim, 1976).

Atropinic properties of drugs are therefore an important cause of paralytic ileus. This may be an idiosyncratic phenomenon as well as dose related, or it may occur when in combination with other drugs predisposing to bowel immobility, such as opiates. Some drugs, most notably the mono-amine oxidase inhibitors, prolong the detoxification of anti-cholinergic drugs and account should also be taken of this (Goodman and Gilman, 1980).

Postoperatively ileus may be prolonged due to concomitant anti-cholinergic therapy being taken by the patient on admission.

Treatment of established anti-cholinergic induced ileus is conservative, as in this case. Little has been published on the effect of the use of anti-cholinesterase drugs such as neostigmine in these patients, although Sriram et al. (1979) have had some success with these drugs and it would seem sound practice to institute such therapy.

\section{Acknowledgments}

I should like to thank Mr A. D. B. Chant for permission to repor on his patient, Professor C. F. George for his encouragement and Mrs S. E. Gough and Miss L. G. Jennings for the typing of the manuscript.

\section{References}

DAGgeTt, P. \& IBRAHIM, S.Z. (1976) Intestinal obstruction complicating orphenadrine treatment. British Medical Journal, 1, 21. GEORGE, C.F. (1980) Drugs causing intestinal obstruction: a review. Journal of the Royal Society of Medicine, 73, 200. 
GeORGE, C.F. (1981) Drugs causing constipation and intestinal obstruction. Prescriber's Journal, 21, 148.

Goodman, L.S. \& Gilman, A. (1980) The Pharmacological Basis of Therapeutics. 6th edn, MacMillan, London. 1980.

MALTBIE, A.A., VARIA, I.G. \& ThOMAS, N.U. (1981) Ileus complicating haloperidol therapy Psychosomatics, 22, 158.

MILNER, G. \& BUCKLER, E.G. (1964) Adynamic ileus and amitriptyline: three case reports. Medical Journal of Australia, I, 921.

MILNER, G. \& HILLS, N.H. (1966) Adynamic ileus and nortriptyline. British Medical Journal, I, 841.
Munster, A. \& Milton, G.W. (1961) Paralytic ileus due to ganglion blocking drugs. Medical Journal of Australia, 2, 210.

SIMPSON, J.A. (1978) Diseases of the nervous system. Textbook of Medical Treatment 14th edn (Ed by S. Alstead \& R.H. Girdwood), Chapter 19, p. 303. Churchill Livingstone, Edinburgh \& London.

SRIRAM, K., SChumer, W., EPhrenPreis, S., Comaty, J.E. \& SHELLER, J. (1979) Phenothiazine effect on gastrointestinal tract function. American Journal of Surgery, 137, 87.

Watson, W.C., KNUTTY, P.K. \& ColClough, R.G. (1977) Does cimetidine cause ileus in the burned patient? Lancet, ii, 720. 